\title{
Karakteristik Permukaan Dan Struktur Mikro Pada Bahan Aluiminium 6061menggunakan Pahat Karbida Dengan Metode Pemesinan Laju Tinggi Dan Pemesinan Kering
}

\section{Surface Characteristics And Micro Structure In Aluiminium Material 6061 Using Carbide Chisel By High-Speed Machining Method And Dry Machinery}

\author{
Booby Umroh * \\ Prodi Mesin, Fakultas Teknik, Universitas Medan Area, Indonesia
}

*Coresponding Email: bobbyumroh@staff.uma.ac.id

\begin{abstract}
Abstrak
Penelitian pemesinan laju tinggi dan kering dengan tujuan untuk kemasan permukaan yang meliputi corak permukaan cacat (defect) yang diakibatkan oleh kondisi pemesinan pada bahan aluminium 6061 menggunakan pahat karbida. Pengumpulan data pengujian pemesinan ini dilakukan menggunakan metode faktorial data sebanyak 8 kali percobaan dengan 3 variabel utama yaitu laju pemotongan(V), laju pemakanan (f) dan kedalaman potong (a) pada tiga tiga tingkat besaran. Dari percobaan yang telah direkomendasikan dengan kondisi pemesinan terbaik maka didapati beberapa Nilai kekasaran permukaan sangat ditentukan oleh aus pahat yang tinggi. Aus pahat yang tinggi (0.129-0.247)sangat berpotensi terjadi cacat berupa koyak permukaan (tearing surface) permukaan benda kerja termesin, pada laju pemakanan yang tinggi terjadi feed mark goresan karena laju pemakanan yang tinggi .Lebar butiran pada mikrostruktur sangat ditentukan oleh kecepatan potong, dimana pada kecepatan potong $\mathrm{V}=1000 \mathrm{~m} / \mathrm{min}$ besarnya butiran terlihat lebih melebar sedangkan pada $\mathrm{V}=1250 \mathrm{~m} / \mathrm{min}$ besar butiran terlihat lebih rapat
\end{abstract}

Kata kunci : pemesinan laju tinggi, pemesinan kering, aluminium 6061, cacat permukaan (defect) koyak permukaan ( tearing surface)

\begin{abstract}
Research of high and dry rate machining for the purpose of surface packaging which includes defects caused by machining conditions on aluminum material 6061 using carbide chisel. The data were collected using factorial method of data 8 times experiment with 3 main variables namely cutting rate ( $V$ ), feed rate (f) and cutting depth (a) at three three level magnitude. From the experiments that have been recommended with the best machining conditions then found some of the value of surface roughness is determined by the high chisel aus. Aus chisel high (0.129-0.247) is highly potential for defects in the form of tearing surface of the machined workpiece, at high feed rate occurs feed mark scratches due to high rate of feeding. The width of grains on the microstructure is determined by cutting speed, where at cutting speed $V=1000 \mathrm{~m} / \mathrm{min}$ the size of the granules look more widespread while at $V=1250 \mathrm{~m} / \mathrm{min}$ large grains look more tightly.
\end{abstract}

Keywords: high speed machining, dry machining, aluminum 6061, surface defect (defect) tearing surface (tearing surface) 
Bobby Umroh, Karakteristik permukaan dan struktur mikro Pada bahan aluiminium 6061menggunakan Pahat ...

How To Cite: Umroh, B (2017). Karakteristik permukaan dan struktur mikro Pada bahan aluiminium 6061menggunakan Pahat Karbida dengan metode pemesinan laju tinggi dan pemesinan kering. Jmemme (Journal Of Mechanical Engineering, Manufactures, Materials And Energy). 1 (2): 57-65 


\section{PENDAHULUAN}

Industri pemotongan logam merupakan bagian penting dalam industry manufaktur untuk memproduksi bagian bagian mesin otomotif. Untuk memenuhi permintaan pasar terhadap produksi perlu dilakukan peningkatan produktifitas yang tinggi dengan memperhatikan keselamatan lingkungan.

Produktifitas yang tinggi akan dicapai dilakukan dengan menggunakan teknologi proses pemesinan terkini yaitu pemesinan laju tinggi yang berhubungan erat dengan laju pemotongan, laju pemakanan dan kedalaman potong yang tinggi selain dari peningkatan produktifitas perlu dilakukan metode untuk keselamatan lingkungan metode ini adalah konsep pemesinan kering. Pemesinan laju tinggi adalah proses pemotongan logam yang dicirikan oleh laju pemotongan yang tinggi dan berhubungan erat dengan jenis bahan

yang dipotong (6), untuk bahan kerja aluminium laju pemotongan pada pemesinan lajuntinggi adalah $>1000$ $\mathrm{m} / \mathrm{min}$. Selanjutnya, pemesinan kering adalah proses pemotongan logam yang

dilakukan tanpa adanya cairan pemotongan yang biasanya digunakan lebih sedikit yaitu $5 \mathrm{ml} / \mathrm{min}$ (minimal quantity lubrication) atau tidak sama sekali digunakan sebagai media pendingin dan media pelumas. Lebih lanjut, pemesinan kering memiliki kelebihan yaitu tidak digunakannya cairan pemotongan berarti dapat mengurangi ongkos produksi sebesar (16-20)\% serta berpengaruh untuk penyelamatan lingkungan karena tidak adanya cairan pemotongan bekas yang dibuang kealam bebas (7) Peneliti terdahulu melakukan kajian pemesinan laju tinggi pada bahan aluminium produksi otomotif dilakukan

untuk meningkatkan produktifitas. Namun penelitian yang dilakukan pada umumnya masih menggunakan cairan pemotongan. (1) melakukan penelitian pemotongan aluminium pada keadaan kering namun tidak menggunakan pemesinan laju tinggi. Implementasi Pemesinan laju tinggi yang

dilakukan pada bahan aluminium pada pemesinan basah memang berhasil meningkatkan produktifitasnya, namun dari aspek penyelamatan lingkungan, cairan pemotongan yang digunakan masih berpotensi mencemari lingkungan. Oleh karena itu perlu dilakukan kajian tentang pemesinan laju tinggi terhadap produk otomotif yang tidak mencemari lingkungan.

Objek yang dikaji pada penelitian dengan topik pemesinan laju tinggi dan pemesinan kering, subjek pada penelitian 
ini difokuskan pada kemasan permukaan(surface integrity) pemesinan yang meliputi defect ( cacat) pada permukaan, lay( corak) keberarahan keberombakan pada benda kerja . Benda kerja yang dipakai pada penelitian ini adalah Aluminium dengan pengenalan $\mathrm{AL}$ 6061. Pada konstruksi rekayasa bahan tersebut lazim digunakan sebagai bahan bagian dari produk otomotif seperti: velg, piston, deksel dan lain sebagainya .

\section{METODE PENELITIAN}

Material benda uji adalah Aluminium 6061 Aluminium jenis ini banyak ditemukan dilapangan dan industri, Pertimbangan pemilihannya adalah karena material baik digunakan pada aplikasi bagian-bagian produk transportasi. Komposisi kimia dan sifat fisika material ini dapat dilihat sebagaimana tertera pada tabel 1 dan tabel 3 berikut ini

Tabel 1. Mekanikal Properties Aluminium
6061
\begin{tabular}{|l|l|}
\hline $\begin{array}{l}\text { Mechanical } \\
\text { Properties }\end{array}$ & Nilai \\
\hline Young Modulus & $69 \mathrm{Gpa}$ \\
\hline tensile strength & $125 \mathrm{MPa}$ \\
\hline yield strength & $55 \mathrm{MPa}$ \\
\hline Elongation & $25-30 \%$ \\
\hline
\end{tabular}

Pahat yang digunakan didasarkan pada pertimbangan sifat pahat sesuai dengan kebutuhan pemakaian. Pahat yang digunakan adalah Karbida dengan Pertimbangan pemilihan bahan pahat didasarkan pada kekerasan panas dan ketahananan aus serta temperatur kerja. Pengenalan pahat diproduksi oleh SANDVIK Coromant Berdasarkan pertimbangan diatas dengan standard ISO K10 maka digunakan pahat karbida tidak berlapis dengan pengenalan DCGX 11 T3 04-AL $r e=0,4 \mathrm{~mm} ; s=4 \mathrm{~mm}$ dan pemegang pahat dengan pengenalan SDJCL 2020K $11\left(-3^{\circ}\right)$

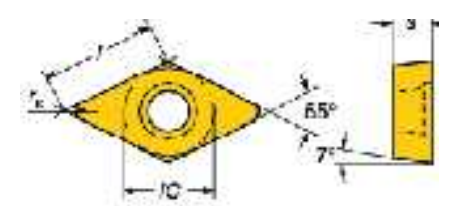

Gambar 1 Geometri pahat Karbida

Tabel 2. Mekanikal Propertis pahat Karbida

\begin{tabular}{|l|l|}
\hline $\begin{array}{l}\text { Mechanical } \\
\text { Properties }\end{array}$ & Nilai \\
\hline Hardnes (HV3) & 1750 \\
\hline Young's modulus (GPa) & 620 \\
\hline Tegangan Retak (Gpa) & 2.4 \\
\hline Konduktifitas termal & $(\mathrm{W} / \mathrm{m} . \mathrm{K}) 9$ \\
\hline
\end{tabular}

Mesin bubut yang digunakan CNC LATE FOCUS dengan putaran maximum 4000 Rpm dengan diameter pencekam 180 mm panjang ruang benda kerja $300 \mathrm{~mm}$ dan daya 3 HP, untuk melihat foto makro menggunakan USB microscop dan melihat kekasaran permukaan menggunakan surface test. Pengujian ini dilakukan dengan membubut cilndrical cutting dengan satu mata pahat potong (single point turning tools) data diambil sebagai berikut:

Table 3. Komposisi material aluminium 6061

\begin{tabular}{|l|l|l|l|l|l|l|l|l|}
\hline $\mathrm{Si}$ & $\mathrm{Fe}$ & $\mathrm{Cu}$ & $\mathrm{Mn}$ & $\mathrm{Mg}$ & $\mathrm{Cr}$ & $\mathrm{Zn}$ & $\mathrm{Ti}$ & $\mathrm{Al}$ \\
\hline 0,65 & 0,70 & $\mathbf{0 , 2}$ & $\mathbf{0 , 1}$ & $\mathbf{0 , 9}$ & $\mathbf{0 , 1}$ & $\mathbf{0 , 1}$ & $\mathbf{0 , 1}$ & sisa \\
\hline
\end{tabular}




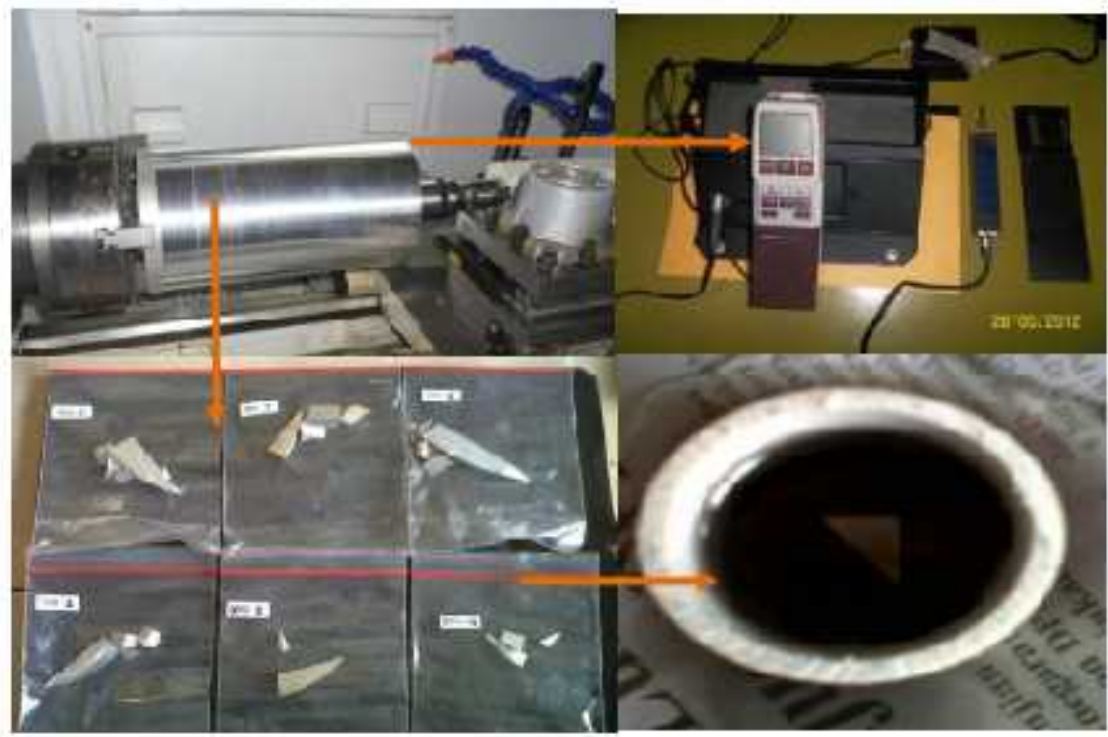

Gambar 2. Set-up Pemesinan dan mounting benda kerja Aluminium 6061

Tabel 4. Kondisi Pemesinan didalam menetukan kondisi maximal dan minimal

\begin{tabular}{|c|c|c|c|c|c|c|c|c|c|c|}
\hline No & $\mathrm{V}(\mathrm{m} / \mathrm{min}))$ & $\mathrm{f}(\mathrm{mm})$ & $\mathrm{a}(\mathrm{mm})$ & $\mathrm{L}(\mathrm{mm})$ & $\mathrm{VB}(\mathrm{mm}$ & $\mathrm{Ra}(\mu \mathrm{m})$ & $\mathrm{Tc}(\min )$ & TC & $\mathrm{Ra} 2$ & VB2 \\
\hline 1 & 1000 & 0.12 & 1 & 270 & 0.021 & 1.33 & 0.951 & - & - & - \\
\hline 2 & 1250 & 0.12 & 1 & 267 & 0.0325 & 1.53 & 0.769 & - & - & - \\
\hline 3 & 1000 & 0.15 & 1 & 258 & 0.027 & 2.15 & 0.739 & - & - & - \\
\hline 4 & 1250 & 0.15 & 1 & 250 & 0.0347 & 2.31 & 0.576 & - & - & - \\
\hline 5 & 1000 & 0.12 & 1.2 & 280 & 0.022 & 1.08 & 0.994 & 18.92 & 1.56 & 0.247 \\
\hline 6 & 1250 & 0.12 & 1.2 & 262 & 0.036 & 1.41 & 0.732 & 9.2 & 1.9 & 0.129 \\
\hline 7 & 1000 & 0.15 & 1.2 & 242 & 0.0287 & 2.27 & 0.683 & - & - & - \\
\hline 8 & 1250 & 0.15 & 1.2 & 275 & 0.366 & 2.31 & 0.645 & - & - & - \\
\hline
\end{tabular}

Data diambil dengan membatasi nilai range pemesinan laju tinggi seperti yang direkomendasikan oleh (Schuzt dan moriwaki 1992) adalah pada laju pemotongan $\mathrm{V}=>1000 \mathrm{~m} / \mathrm{min}$ sedangkan nilai kedalaman potong ditentukan dengan variasi $\mathrm{a}=1-1.5 \mathrm{~mm}$, laju pemakanan dengan range $\mathrm{f}=0.120 .23 \mathrm{~mm} / \mathrm{rev}$.

\section{HASIL DAN PEMBAHASAN}

\section{Kondisi} pemesinan

sangat

dipengaruhi bebarapa faktor, selain dari variable terikat dimana $\mathrm{V}, \mathrm{f}$ dan $\mathrm{a}$, ada juga variabel bebas yang menjadi faktor utama terjadinya kekasaran permukaan. Dalam hal ini variabel bebas yang diambil adalah waktu potong (tc) dan aus pahat (VB). Kedua variabel ini merupakan nilai yang tidak ditentukan oleh peneliti namun dari sisi lain perlu dilakukan pengkajian pengaruh dari waktu potong dan aus 
pahat terhadap kekasaran permukaan. Pada gambar 3a. diperlihatkan grafik kecepatan potong terhadap kekasaran permukaan tidak selamanya nilai tinggi kecepatan potong mempengaruhi keksaran permukaan.

Selanjutnya grafik aus pahat (VB) terhadap keksaran permukaan memperlihatkan pada gambar $3 \mathrm{~b}$. bahwa semakin besar aus pahat yang terjadi akibat pemesinan maka semakin besar pula kekasaran permukaan yang diperoleh. Hal ini menyatakan bahwa semakin besar nilai kekasaran permukaan sangat dipengaruhi oleh besarnya nilai aus pahat. Pada variabel bebas berikutnya adalah waktu potong (tc) terhadap kekasaran permukaan diperlihatkan pada gambar 3 c. dinyatakan bahwa semakin cepat waktu potong pada saat pemesinan sangat mempengaruhi nilai kekasaran permukaan. Kondisi ini juga menandakan ketergantungan antara laju pemakanan dan panjang benda kerja yang mempengaruhi nilai kekasaran permukaan yang terjadi.

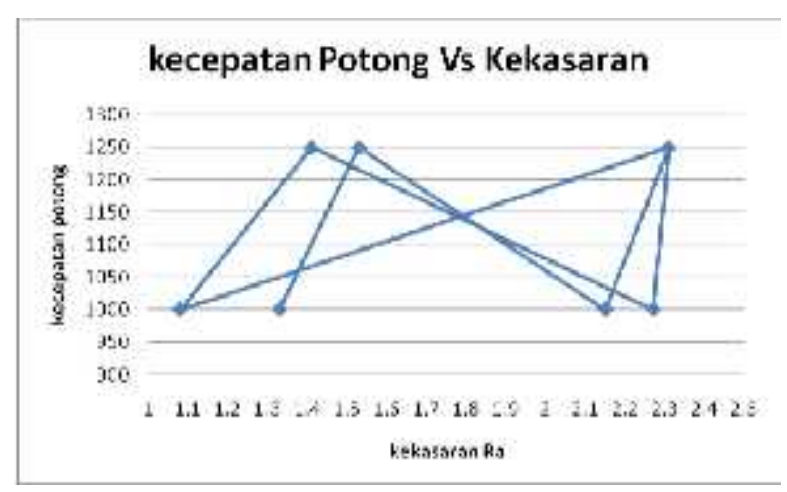

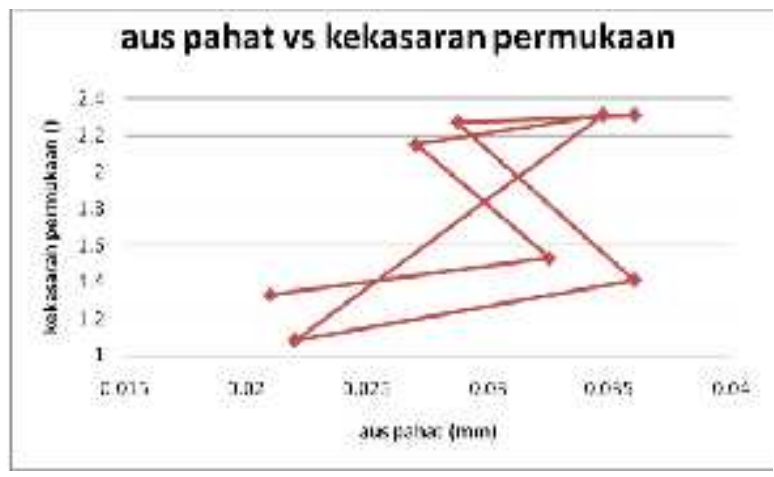

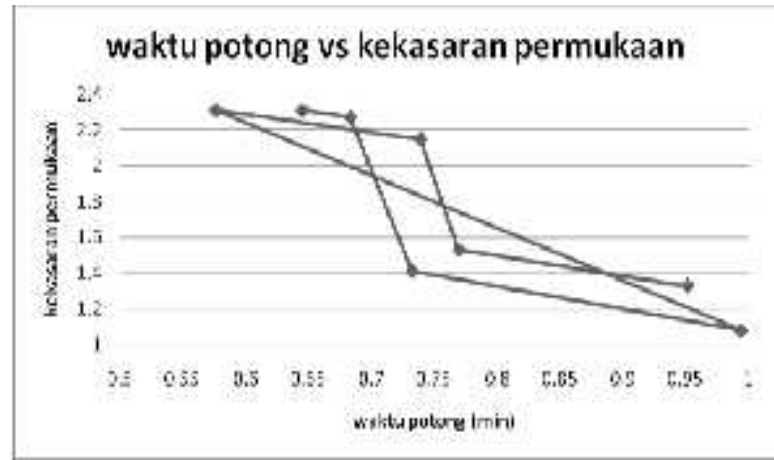

Gambar 3. Grafik kondisi pemesinan terhadap kekasaran permukaan

\section{Corak Permukaan}

Pemeriksaan lebih lanjut pada permukaan benda kerja termesin adalah analisa topografi permukaan untuk melihat corak (keberarahan), dari permukaan hasil pemesinan. Sampel permukaan untuk uji corak ini diambil dari setiap kondisi pemotongan.. Pengamatan topografi permukaan untuk mempelajari corak permukaan benda kerja termesin dilakukan dengan Scaning Electron Microscopy (SEM). Pada kondisi terendah ini $\mathrm{V}=1000 \mathrm{~m} / \mathrm{min}, \mathrm{f}=0.12 \mathrm{~mm} \quad \mathrm{a}=1 \mathrm{~mm}$ sebagaimana diperlihatkan pada gambar 4.Batas geometri hidung pahat tidak begitu terlihat.

Kondisi ini juga memperlihatkan corak (keberarahan) yang terjadi pada 
kondisi terendah ini merupakan kondisi kurang baik dan setelah dilakukan pengukuran pada benda kerja menggunakan surface roughnes nilai kekasarannya adalah $\quad 1.34 \quad \mu \mathrm{m}$. Nilai kekasaran ini sebenaranya nilai yang masih direkomendasikan oleh kalpakjian 2006 namun dari sisi analisa topografi banyaknya terdapat corak pada permukaan termesin

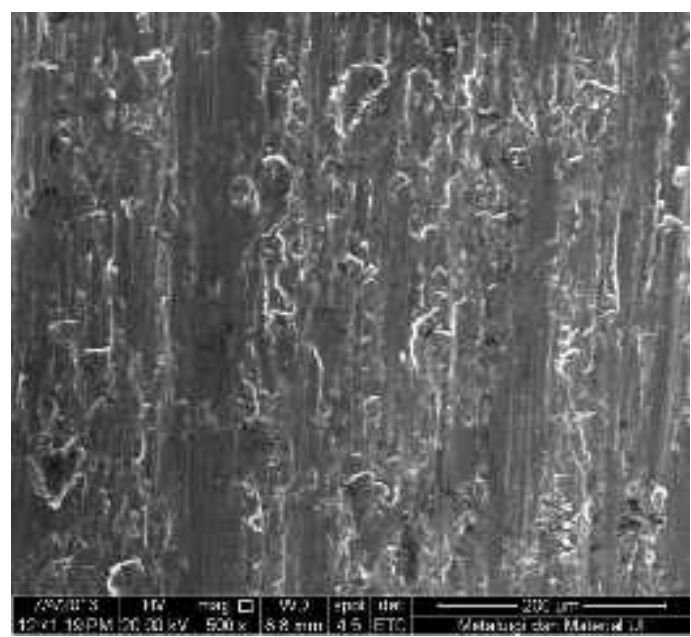

Gambar 4. Corak permukaan kondisi 1

Pada kondisi pertama dengan kondisi $\mathrm{V}=1000 \mathrm{~m} / \mathrm{min}, \mathrm{f}=0.12 \mathrm{~mm}$ dan $\mathrm{a}=1 \mathrm{~mm}$ hanya dibedakan oleh kedalaman potong yaitu a=1.2 mm. Gambar foto mikro memperlihatkan bahwa batas geometri hidung pahat juga tidak terlihat jelas, hal ini membuktikan bahwa geometri hidung pahat juga tidak ditentukan oleh kedalaman potong. Dari sisi kekasaran permukaan pada saat benda termesin kondisi kekasaran permukan pada saat waktu potong 1 menit adalah Ra=1.08 $\mu \mathrm{m}$, sedangkan pada waktu potong 18.92 menit kekasaran permukaan $\mathrm{Ra}=1.56 \mu \mathrm{m}$.

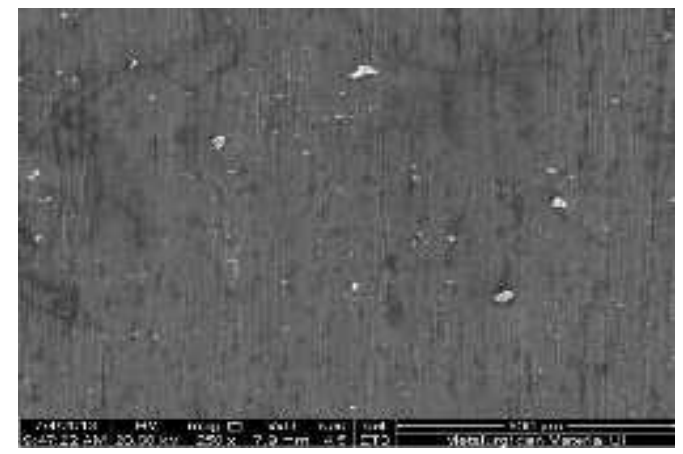

Gambar 5.Corak permukaan kondisi 5

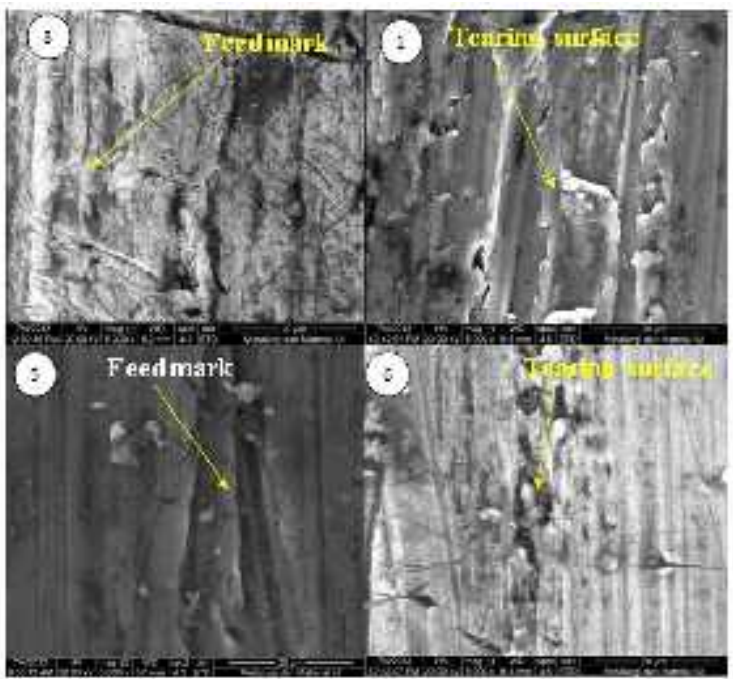

Gambar 6 cacat permukaan pada 4 kondisi termesin

\section{Defect (cacat permukaan)}

Ketidak seimbangan pahat akibat getaran antara pahat dan benda kerja yang disebabkan oleh beban dinamik hasil pemotongan daripada kondisi pemotongan yang tinggi adalah salah satu faktor yang menyebabkan terjadinya cacat pada permukaan benda termesin. Selain itu keausan dan kerusakan pahat dapat merupakan suatu faktor yang dominan penyebab kerusakan permukaan benda 
termesin. Hasil pemeriksaan pada 4 kondisi memperlihatkan masing-masing kondisi topografi permukaan.

terjadinya koyak permukaan (tearing surface) pada benda kerja. Kondisi ini memiliki perbedaan jenis koyak permukaan pada kondisi 1 dan 6. Koyak permukaan pada kondisi 6 diakibatkan oleh aus pahat yang bersentuhan dengan benda kerja, sedangkan pada kondisi 1 jenis koyak permukaan merata, kondisi kerusakan ini masih dalam penyelidikan, Pada gambar 6 memperlihatkan bahwa pada kondisi pemesinan 8 dan 5 memiliki kesamaan kerusakan yaitu terjadi nya kerusakaan permukaan akibat laju pemakanan yang sehingga terjadinya aus pahat sehingga membentuk berupa garisan atau cakaran yang disebut dengan Feedmark hal ini terjadi pada kondisi 5, sedangkan pada kondisi 8 kerusakan permukaan disebabkan oleh laju pemakanan yang sangat tinggi yaitu $\mathrm{f}=0.15$ mm. pada kondisi 1 dan kondisi 6 memiliki perbedaan pada bentuk cacat pada permukaan aluminium 6061 yaitu untuk itu perlu dilakukan penelitian lebih lanjut, kondisi terendah dari seluruh kondisi dengan pahat yang masih baru tetapi memiliki topografi permukaan yang kurang baik.

\section{Mikrostruktur Aluminium 6061}

\section{Setelah Pemesinan}

Mikrostrukstur pada bahan aluminium 6061 memiliki perbedaan padamasing masing kondisi pemesinan. Namun dari 4 kondisi pemesinan yang diamati ada beberapa perbedaan pada butiran aluminium 6061 yang dimesin menggunakan pahat karbida yaitu dari jenis butiran-butiran mikrostruktur. Dari butiran-butiran seperti Gambar 4.8 dibawah ini, besar butiran sangat ditentukan oleh kecepatan potong. Pada kecepatan potong $\mathrm{V}=1000 \mathrm{~m} / \mathrm{min}$ besar butiran lebih lebar dan pada kecepatan $\mathrm{v}=1250 \mathrm{~m} / \mathrm{min}$ besar butiran terlihat lebih banyak dan rapat.
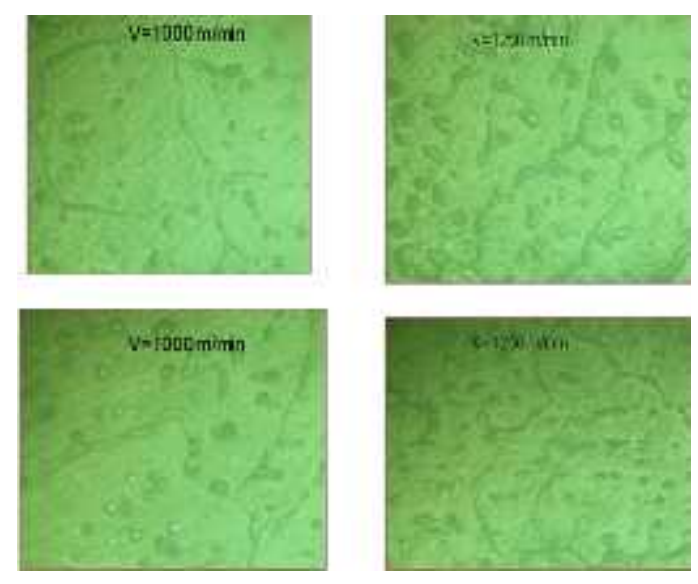

Gambar . 7 gambar Mikrostruktur Aluminium 6061

\section{SIMPULAN}

Aus pahat sangat mentukan kekasaran permukaan, sehingga dapat dipastikan pada beberapa kondisi aus pahat yang tinggi menyebabkan kekasaran 
pada permukaan benda kerja aluminium

6061

Aus pahat yang tinggi

(0.1290.247)sangat berpotensi terjadi cacat berupa koyak permukaan (tearing surface) permukaan benda kerja termesin, pada laju pemakanan yang tinggi terjadi feed mark goresan karena laju pemakanan yang tinggi

Lebar butiran pada mikrostruktur sangat ditentukan oleh kecepatan potong, dimana pada kecepatan potong $\mathrm{V}=1000$ $\mathrm{m} / \mathrm{min}$ besarnya butiran terlihat lebih melebar sedangkan pada $\mathrm{V}=1250 \mathrm{~m} / \mathrm{min}$ besar butiran terlihat lebih rapat.

\section{DAFTAR PUSTAKA}

[1]F. Itoigawa et. al effects and mechanisms in minimal quantity lubrication machining of an aluminium alloy Journal of Materials Processing Technology 2006

[2]H.Kishway et. al Effect of coolant strategy on tool performance, chip morphology and surface quality during high speed machining of A356 aluminium alloy Journal of Materials Processing Technology 2005

[3]Jianwen HU and Kevin Chou Y Characterizations of cutting tool flank wear-land contact Journal of Materials Processing Technology 2007

[4]Kalpakjian. S. Manufacturing Process for Engineering and Technology, third Edition, Addison Wesley Publishing Company.1995.

[5] Rochim T, teori dan teknologi permesinan, HEDS. 1993.

[6]Schultz, H. ;and Moriwaki, T. High speed Machining. Annals of the CIRPP.1992.

[7]Sreejith, P.S and Ngoi, B.K.A.. Dry machining, machining of the future. J. Mater.Proc. Technologi. 2000.

[8]Tugrul O" zel*, Yig it Karpat. Predictive modeling of surface roughness and tool wear in hard turning using regression and neural networks. International Journal of Machine Tools \& Manufacture 45 (2005) 467-479 